\title{
HLA-A*2402-Restricted CDCA1-A24-56 Peptide Vaccine
}

National Cancer Institute

\section{Source}

National Cancer Institute. HLA-A*2402-Restricted CDCA1-A24-56 Peptide Vaccine. NCI

Thesaurus. Code C94223.

A cancer vaccine containing the HLA-A 2402 -restricted peptide epitope derived from cell division associated gene 1 (CDCA1), with potential immunostimulatory and antitumor activities. Upon administration, HLA-A*2402-restricted CDCA1-A24-56 peptide vaccine may stimulate a cytotoxic $T$ lymphocyte $(C T L)$ response ag ainst CDCA1-expressing tumor cells, resulting in tumor cell lysis and decreased tumor cell proliferation. HLA$A * 2402$ is an MHC class I molecule that presents antigenic peptides to CD8+ T cells; epitope design restricted to epitopes that bind most efficiently to HLA-A*2402 may improve antigenic peptide immunogenicity. 